\title{
Malignant epithelial-stromal renal tumor: Progressive atypical features in a case of male patient with fatal outcome
}

\author{
Ivan Gallegos ${ }^{1}$, Edgardo Mancilla ${ }^{1}$, Cristina Fernandez ${ }^{1}$, Pablo Diaz $^{2}$ \\ 1. Pathology Department, Clinical Hospital of University of Chile, Chile. 2. Urology Department, Clinical Hospital of \\ University of Chile, Chile. \\ Correspondence: Ivan Gallegos. Address: Santos Dumont 999, Independencia, Santiago, Chile. \\ E-mail: igallegosmendez@gmail.com
}

Received: August 12, 2014

Accepted: September 9, 2014

Online Published: September 26, 2014

DOI : $10.5430 /$ crcp.v2n1p43

URL: http://dx.doi.org/10.5430/crcp.v2n1p43

\begin{abstract}
Mixed epithelial-stromal tumors of kidney are rare neoplasm usually described in postmenopausal females under estrogenic therapy. Although tumor behavior is in general benign, sporadic cases with an aggressive behavior have been described. The present case is a 41-year-old male with lumbar pain, hematuria and lump in left kidney. Tumor spread assessment evidenced no findings and therefore radical nephrectomy was performed. Grossly tumor was peripherally located, whitish, round-shaped, measuring $9 \mathrm{~cm}$. It showed spread to the pyelocalyceal system and necrotic areas. Histologically consisted of biphasic neoplasm, with epithelial component of branching ducts that covered a moderately cellular and partly spindle-cell stroma, with focal areas of marked atypia and prominent mitotic activity. Immunostains were positive for Pancytokeratin and Keratin 7 in the epithelial component, positive for Vimentin in both epithelial and stromal components, and positive for Actin only in isolated stromal cells. Immunostains were negative for Estrogen and Progesterone Receptors and CD99. Ki-67 was positive in $60 \%$ of pleomorphic stromal areas, in $20 \%$ of low-grade stromal areas and in $<5 \%$ of the epithelial component. Disease progressed in a few months with bilateral lung metastases and death. The present case is reported by to be a very rare case with malignant behavior and fatal outcome in a male patient. The aim of the present work is to contribute to the knowledge and characterization of such lesions.
\end{abstract}

\section{Key word}

Renal adenosarcoma, Malignant epithelial-stromal tumor, Ki67, Fatal outcome

\section{I ntroduction}

Mixed epithelial and stromal tumors of the kidney are uncommon biphasic lesions and usually have a benign behavior. Michal and Syrucek first used the term Mixed Epithelial and Stromal Tumor of the Kidney in 1998 in a case report and then several larger series has been described ${ }^{[1]}$. Some findings overlap with those of cystic nephromas ${ }^{[2,3]}$. 


\section{Clinical history}

A 41-year-old male patient without previous malignancies and a history of urolithiasis and obesity presented with left flank pain and hematuria. An abdomen computed tomography scan evidenced a mass on the upper pole of the left kidney measuring $9 \mathrm{~cm}$ in diameter. The subsequent spread assessment showed negative results, and therefore the patient underwent a radical nephrectomy.

\section{Materials and methods}

Complete biopsy protocol was performed including macroscopic examination, ordinary tissue process and stains with Hematoxylin eosin. Immunohistochemistry to two tumor blocks according to standard protocols were performed for Vimentin, CD99, MIB1/Ki67, wide range keratins, Progesterone receptors, Estrogen receptors and Smooth muscle actin.

\section{Results}

The surgical specimen weighted $904 \mathrm{~g}$. The kidney measured $16 \mathrm{~cm} \times 9 \mathrm{~cm} \times 8 \mathrm{~cm}$ and evidenced a round-shaped tumor on the upper pole. It measured $8 \mathrm{~cm}$ in largest diameter. On cut surface the tumor was whitish with reddish areas and necrotic foci (see Figure 1 and 2). Additionally the tumor showed gross extension towards the pyelocalyceal system, with a polypoid protrusion that ulcerated the mucosa. The renal vein, the ureter, perirenal adipose tissue and adrenal gland were uninvolved.

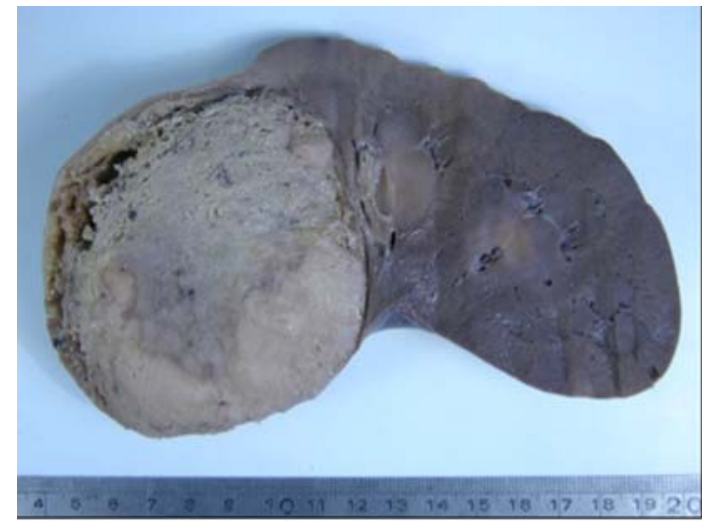

Figure 1. Tumor on the upper renal pole. Cut surface solid and cystic, heterogeneous, with some necrotic areas.

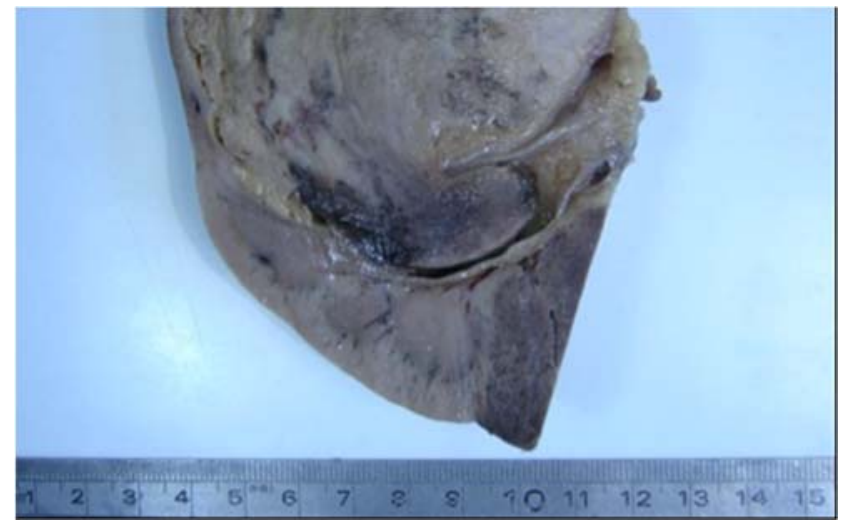

Figure 2. Polypoid tumor protrusion towards the pyelocalyceal system.

Microscopically (see Figure 3 a to i) the tumor showed a biphasic pattern. The epithelial component consisted of irregular branching ducts, arrayed in retiform areas, lined by cuboidal cells with ovoid nuclei. Some of the nuclei were indented. Mitoses were scant. There were occasional papillary structures without associated atypia. The lumen of tubules contained focal eosinophilic material. The stromal component was variably cellular and included three different areas. One moderately cellular area had spindle-shaped cells, ill-defined cytoplasmic outlines, ovoid nuclei with coarse chromatin and less than 5 mitotic figures per 10 high power fields; some few necrotic areas with cholesterol crystals were also present. Second type of stromal areas had more pleomorphic cells, some of them multinucleated, surrounded by a myxo-chondroid matrix. In such areas the epithelial component was similar to the above described but its proportion was decreased and there were more stromal necrotic areas. Finally, a third type of stromal nodular area showed stromal overgrowth and almost absence of epithelial structures. This area was frankly anaplastic with spindle and epithelioid cells, some of them markedly pleomorphic, multinucleated and bizarre, with prominent atypical mitotic figures reaching an average of 30 in 10 high power field. There were no evidences of vascular invasion, capsule involvement or extension towards the perirenal adipose tissue. The urothelium was reactive at the focus of tumor penetration. The urothelium looks stratified, comprising large cells with prominent nucleolus and cytoplasmic eosinophilia, very different to cuboidal epithelial component of tumor. 


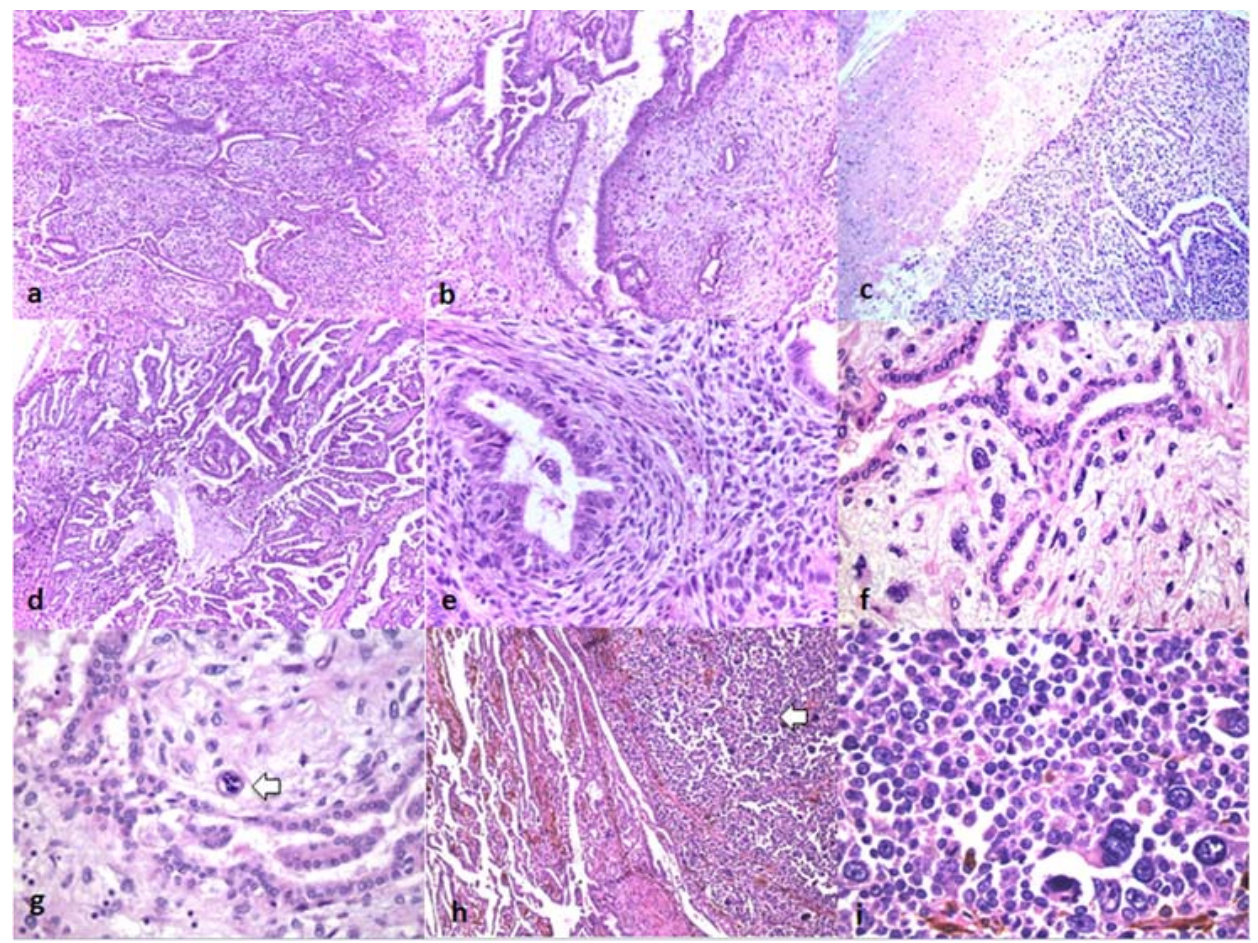

Figure 3. (a-b) Biphasic tumor. Tubular-retiform areas mixed with variable cellularity of stroma. (c) Focal necrotic areas. (d) Epithelial papillary zone. (e) Epithelial tubules with small and monomorphic nucleus and low grade spindle stromal cells. (f) Myxo-chondroid stromal area with more pleomorphic cells. (g) Atypical mitosis in stromal cell. (h-i) Tumor nodule of pleomorphic and multinucleate stromal cells. Note absence of epithelial elements.

Immunohistochemically (see Figure 4), Wide range cytokeratin (AE1/AE3 clone) and Cytokeratin 7 were positive only in epithelial elements. Both the stromal as well as the epithelial elements were immunoreactive for antibodies against Vimentin, except in the more pleomorphic tumor cells. Actin expression was focally positive in the low grade stromal elements. Expression of Estrogen and Progesterone Receptors, and CD99 was negative in both components. Proliferation index through Ki-67 (MIB1) staining was positive in $60 \%$ of pleomorphic stromal areas, in $20 \%$ of low-grade stromal areas and in $<5 \%$ of the epithelial component.

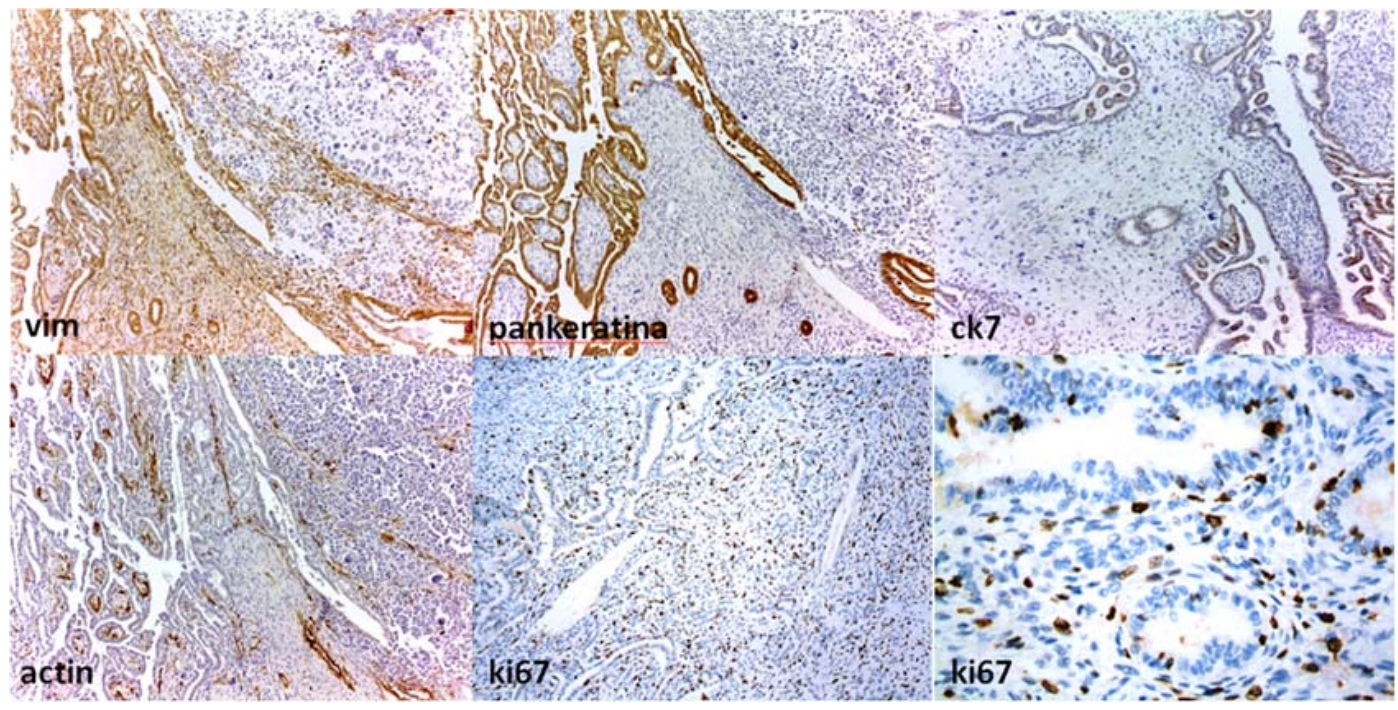

Figure 4. Immunohistochemical results. Vimentin: Positivity in epithelial and stromal components, except pleomorphic zone (arrow). Pancitokeratin and CK7: Positivity in epithelial cells. Actin: Focal positivity in low grade stromal cells. Ki67: Predominant positivity in stromal elements over than epithelial cells. 


\section{Discussion}

Mixed epithelial and stromal tumors of the kidney are more common among middle-aged and older women, in a female to

male ratio of 6-10 to 1 , however the age of onset ranges between the second and the ninth decade of life ${ }^{[4,5]}$. Symptoms may vary from an incidental finding to hematuria and flank pain.

Grossly, mixed tumors are centrally located, well-circumscribed, non-capsulated lesions. Their size is variable, between less than $3 \mathrm{~cm}$ and $14 \mathrm{~cm}$ in greatest diameter. Usually, the greater the size, the more the cystic component is predominant $^{[1,2,6]}$.

Microscopically lesions are solid and cystic. The stromal component is spindle-shaped with variably cellularity. Some types of different stroma have been decribed: ovarian-like, myxoid, myofibroblastic and hyalinizing. The epithelial component is arranged in cysts or tubules, with an epithelial lining that may be cuboidal, columnar or urothelial ${ }^{[1,2,6]}$. Some others types of epithelium have been described like endometrioid, tubal, mucinous, intestinal and squamous ${ }^{[2,3]}$.

Immunohistochemical profile shows: In epithelial cells positivity for wide spectrum keratins, Cytokeratin 7, high molecular weight keratins and negativity for Cytokeratin 20, Estrogen and Progesterone Receptors. In stromal cells positivity for Smooth Muscle Actin, Vimentin, and variable expression of CD34, Estrogen and Progesterone Receptors; negativity for HMB-45, Melan-A, WT1, S-100, CD99 and Ulex ${ }^{[2,3,7,8]}$. In the present case, the tumor had an immunehistochemical profile very similar to that of previously reported cases. We can observe that there were no significant immunohistochemical differences between the low and high grade stromal areas.

The usual behavior of such lesions is benign, however some malignant cases have been described ${ }^{[9,10]}$ even with fatal outcome $^{[11]}$. Tumor features that support a malignant behavior are increased cellularity, cytologic atypia, round-shaped or ovoid nucleus with a prominent nucleolus and high mitotic count of $15-25$ mitoses per $10 \mathrm{HPF}^{[4]}$. In the present case, the stromal component showed a progression of malignant features supported by increasing stromal cellularity, necrosis, pleomorphism and mitotic count, with decreasing epithelial component. Such pattern suggests a certain dedifferentiation of the stromal component similar to what was described by Michal et al. ${ }^{[2]}$. Differential diagnosis in malignant cases should contemplate entities such as renal cell carcinoma with sarcomatoid differentiation (RCCs), biphasic synovial sarcoma (BSS) of the kidney and metastatic biphasic malignant tumors.

Surgical treatment is the therapeutic option for such lesions and is usually curative.

The present case had a rapid progression. Lung metastases and left pleural effusion presented one month after diagnosis. Response to chemotherapy with doxorrubicina and ifosfamide was very poor, with initial little response and fast progression with death supervened six months after diagnosis. Unfortunately, no postmortem examination was carried out.

The majority of reported cases have been treated with only surgery. There are few experiences using chemotherapy on those cases, with some reported cases not associated to significant response. In one case a relapsed tumor was treated with chemo and radiotherapy with partial response for some weeks ${ }^{[12,13]}$.

To summarize, we present this case of malignant epithelial-stromal tumor of kidney arising in a male patient, with progressive atypical histologic features and fatal outcome over a few months. The aim of the present work is to shed light on the knowledge and characterization of such unusual tumors.

\section{References}

[1] Michal M, Hes O, Bisceglia M, et al. Mixed epithelial and stromal tumors of the kidney. A report of 22 cases. Virchows Arch. 2004; 445: 359-367. PMid: 15322873. http://dx.doi.org/10.1007/s00428-004-1060-y 
[2] Antic T, Perry KT, Harrison K, et al. Mixed epithelial and stromal tumor of the kidney and cystic nephroma share overlapping features. Arch Pathol Lab Med. 2006; 130: 80-85. PMid: 16390243.

[3] Montironi R, Mazzucchelli R, Lopez-Beltran A, et al. Cystic Nephroma and Mixed Epithelial and Stromal Tumour of the Kidney: Opposite Ends of the Spectrum of the Same Entity? European Urology. 2008; 54: 1237-1246. PMid: 18006141. http://dx.doi.org/10.1016/j.eururo.2007.10.040

[4] Mohanty SK, Parwani AV. Mixed epithelial and stromal tumors of the kidney: an overview. Arch Pathol Lab Med. 2009; 133: 1483-1486. PMid: 19722760.

[5] Portier BP, Hansel DE, Zhou M, et al. Mixed Epithelial and Stromal Tumor of the Kidney. The Journal of Urology. 2009; 181(4): 1879-1880. PMid: 19233412. http://dx.doi.org/10.1016/j.juro.2009.01.004

[6] J.N. Eble. Mixed epithelial and stromal tumour. In: John N. Eble, Guido Sauter, Jonathan I. Epstein, Isabell A. Sesterhenn. Pathology and Genetics of Tumours of the Urinary System and Male Genital Organs. Lyon, IARC Press. 2004; 77-78.

[7] Turbiner J; Amin MB; Humphrey PA, et al. Cystic Nephroma and Mixed Epithelial and Stromal Tumor of Kidney: A Detailed Clinicopathologic Analysis of 34 Cases and Proposal for Renal Epithelial and Stromal Tumor (REST) as a Unifying Term. American Journal of Surgical Pathology. 2007; 31(4): 489-500. PMid: 17414095. http://dx.doi.org/10.1097/PAS.0b013e31802bdd56

[8] Picken MM, Fresco R. Mixed epithelial and stromal tumor of the kidney: preliminary immunohistochemical and electron microscopic studies of the epithelial component. Ultrastructural Pathology. 2005; 29: 283-286. PMid: 16036882. http://dx.doi.org/10.1080/01913120590951275

[9] Toshiro, et al. Malignant mixed epithelial and stromal tumor of the kidney: Report of the first male case. International Journal of Urology. [serial online] September 2012. http://dx.doi.org/10.1111/j.1442-2042.2012.03155.x

[10] Sukov WR, Cheville JC, Lager DJ, et al. Malignant mixed epithelial and stromal tumor of the kidney with rhabdoid features: report of a case including immunohistochemical, molecular genetic studies and comparison to morphologically similar renal tumors. Hum Pathol. 2007; 38: 1432-1437. PMid: 17707262. http://dx.doi.org/10.1016/j.humpath.2007.03.022

[11] Nakagawa T, Kanai Y, Fujimoto H, et al. Malignant mixed epithelial and stromal tumours of the kidney: a report of the first two cases with a fatal clinical outcome. Histopathology. 2004; 44: 302-304. PMid: 14987239. http://dx.doi.org/10.1111/j.1365-2559.2004.01782.x

[12] Yap YS, Coleman M, Olver I. Aggressive mixed epithelial-stromal tumour of the kidney treated with chemotherapy and radiotherapy. Lancet Oncol. 2004; 5: 747-749. http://dx.doi.org/10.1016/S1470-2045(04)01651-1

[13] Suzuki T, Hiragata S, Hosaka K, et al. Malignant mixed epithelial and stromal tumor of the kidney: the second male case and review of literature. Int J Clin Exp Pathol. 2014; 7(5): 2658-2663. 